\title{
Profunda femoral arteriovenous fistula after percutaneous arterial and venous catheterization
}

\author{
U. Thadani and A. E. Pratt \\ From the Cardiac and Radiodiagnostic Departments, Hull Royal Infirmary, Hull, Yorkshire
}

$A$ case is described of a profunda femoral arteriovenous fistula which developed within 7 days of percutaneous catheterization of both femoral artery and vein, and which was successfully treated by surgery. Though this is a rare complication of the Seldinger technique, it is readily amenable to surgical cure.

Percutaneous venous and retrograde arterial catheterization by the Seldinger technique (Seldinger, 1953), or its modification, is a routine procedure in many cardiovascular diagnostic and research laboratories. The incidence and nature of complications after these procedures vary from one group of investigators to another. Reports and reviews of such complications are available (Peirce, 1951; Peirce and Ramey, 1953; Odman, 1958; Gregg, 1960; Amplatz, 1962; Venables and Hiller, 1963; Lang, 1963; Luke and McGraw, 1963; McGraw, 1963; Kottke, Fairbairn, and Davis, 1964; Halpern, 1964; Mortensen, 1967; Burchell and Ongley, 1968; Ross, 1968; Braunwald et al., 1968; Bourassa, Lespérance and Campeau, 1969; Simovitch et al., 1970). Temporary arterial spasm, immediate or delayed haemorrhage, arterial and venous thrombosis, embolism, laceration of the artery or vein, perforation of the aortic arch, the development of false or true aneurysms, arteriovenous fistulae, and a variety of cardiac arrhythmias are recorded. Localized wound infection leading to arterial wall damage (Gregg, 1960) and fracture of guide wires or catheters sometimes occurs. Lang (1963) in a survey of complications that arose in II,402 percutaneous retrograde arteriography studies revealed a mortality rate of 0.06 per cent.

Only 4 cases of femoral arteriovenous fistulae after percutaneous retrograde femoral catheterization have been documented in English (Peirce, 195I; Peirce and Ramey, 1953; Ross, 1968). The present case is reported to draw attention again to this rare complication.

\section{Case report}

A 50-year-old man began to experience recurrent syncopal attacks in April 1970. He was then found to be moderately hypertensive (BP 190/120 $\mathrm{mmHg}$ ) with evidence of mild to moderate aortic valve stenosis.

To assess the severity of the aortic valve lesion, right and left cardiac catheterization studies were carried out on 2 June 1970. In view of previous varicose vein operations with ligation of both saphenous veins, transseptal catheterization was performed by the percutaneous introduction of a yellow Kifa catheter and a Ross needle into the right femoral vein and subsequently into the left atrium. A yellow Kifa catheter was also introduced into the right femoral artery by the standard Seldinger technique (Seldinger, 1953). No difficulties or complications were observed during or immediately after these procedures.

A week later (IO June 1970) he developed a persistent ache, aggravated on walking, over the upper medial aspect of the right thigh. On examination all the pulses were easily palpable. However, a continuous thrill and murmur were detected just below the inguinal ligament over the femoral artery, and a femoral arteriovenous fistula was suspected. An aortic angiogram (via left femoral retrograde percutaneous catheterization) confirmed the presence of an arteriovenous fistula at this site (Fig. I a and b). Surgical exploration subsequently revealed an arteriovenous fistula between the posterior aspect of the profunda femoris medial to it. The fistula was closed, though some difficulty was experienced in repairing the posterior wall of the artery. The postoperative course was uneventful

\section{Discussion}

Peirce (195I) reported the developement of a femoral artery-circumflex iliac vein fistula in a hypertensive patient 28 days after performing an aortogram by percutaneous retrograde femoral (arterial) catheterization. Peirce and Ramey (1953 described the developement of an arteriovenous fistula between the femoral 


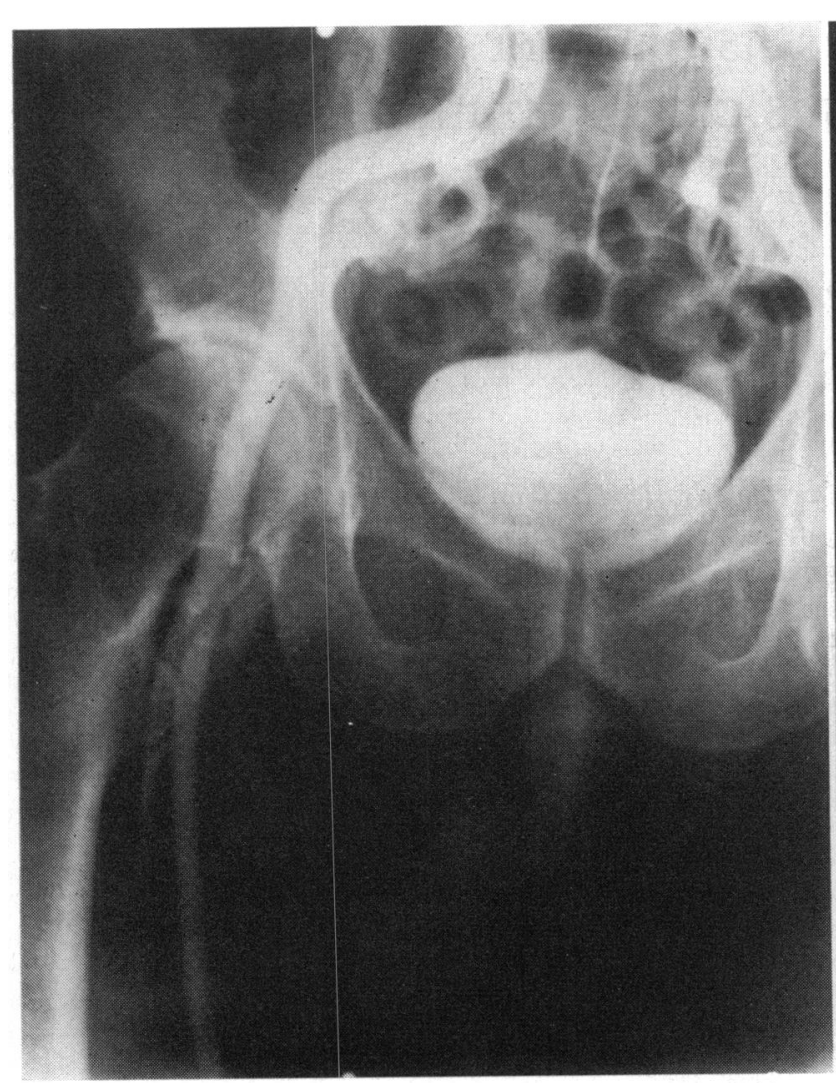

(a)

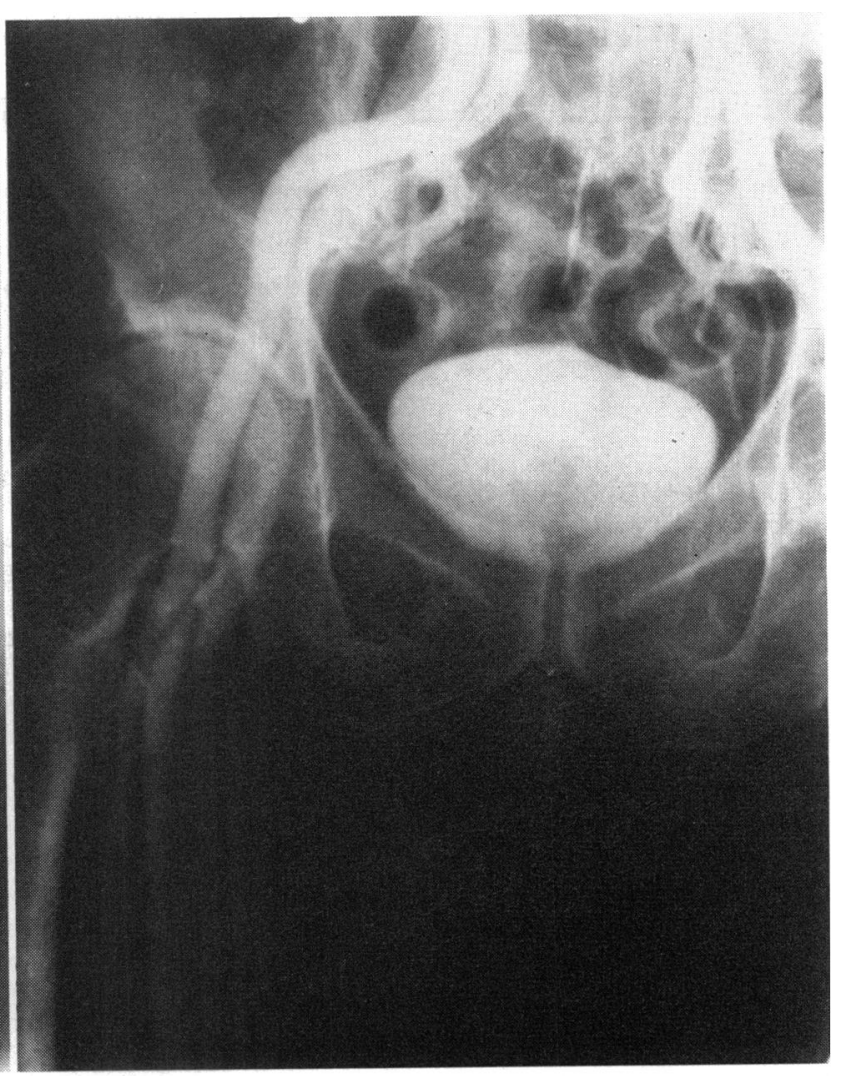

(b)

FIG. I (a) Early, (b) late phase of aortogram, showing right femoral arteriovenous fistula.

artery and a branch of the saphenous vein 27 days after a similar investigation. Braunwald and Gorlin (1968) and Ross (1968) in a review of $I, 855$ patients who had percutaneous venous and 1,460 patients with percutaneous retrograde femoral arterial catheterization found only two further instances of arteriovenous fistulae. Both of these patients had rheumatic heart disease and this complication followed deliberate entry of both the femoral vein and artery. Halpern (1964), however, found no example of this lesion in 1,000 patients who had undergone percutaneous femoral arterial and venous catheter studies.

Our patient, a hypertensive, with chronic deep vein insufficiency of the lower limbs, had undergone both percutaneous venous and retrograde arterial catheterization. In all probability the formation of a haematoma between the two puncture sites aids the development of such a fistula, particularly if haemostasis has not been complete and the arterial and venous pressures are excessively high.

Since early surgical repair of an arterio- venous fistula is often a simple procedure it seems advisable always to consider this lesion after percutaneous retrograde femoral arterial and/or venous catheterization at routine follow-up examination of the puncture site.

We are grateful to Dr. C. P. Aber for allowing us to publish this case and to Mr. A. Pollock who performed the operative repair.

\section{References}

Amplatz, K. (1962). Percutaneous arterial catheterization and its application. American fournal of Roentgenology, Radium Therapy, and Nuclear Medicine, 87, 265.

Bourassa, M. G., Lespérance, J., and Campeau, L. (1969). Selective coronary arteriography by the percutaneous femoral artery approach. American fournal of Roentgenology, Radium Therapy, and Nuclear Medicine, 107, 377.

Braunwald, E., and Gorlin, R. (1968). Total population studied, procedures employed and incidence of complications. In Co-operative study on cardiac catheterization. Edited by E. Braunwald and H. J. C. Swan. Circulation, 37, Suppl. III, 8.

Braunwald, E., Gorlin, R., McIntosh, H. D., Ross, R. S., Rudolph, A. M., and Swan, H. J. C. (I968). Summary. In Co-operative study on cardiac 
catheterization. Edited by E. Braunwald and H. J. C. Swan. Circulation, 37, Suppl. III, 93.

Burchell, H. B., and Ongley, P. A. (1968). Editorial: The Supplement on complications of cardiac catheterization. Circulation, 37, 675.

Gregg, D. McC. (1960). Thoracic aortography in adults - technical aspects. British fournal of Radiology, 33, 531 .

Halpern, M. (1964). Percutaneous transfemoral arteriography; an analysis of the complications in 1,000 consecutive cases. American fournal of Roentgenology, Radium Therapy, and Nuclear Medicine, 92, 918.

Kottke, B. A., Fairbairn, J. F., and Davis, G. D. (1964). Complications of aortography. Circulation, 30, 843 .

Lang, E. K. (1963). A survey of the complications of percutaneous retrograde arteriography - Seldinger technic. Radiology, 81, 257.

Luke, J. C., and McGraw, J. Y. (1963). Complications following catheter angiography. Archives of Surgery, 86, 414.

McGraw, J. Y. (1963). Arteriography of peripheral vessels: a review with report of complications. Angiology, 14, 306.

Mortensen, J. D. (1967). Clinical sequelae from arterial needle puncture, cannulation, and incision. Circulation, 35, 1118.
Ödman, D. (1958). Percutaneous selective angiography of the coeliac artery. Acta Radiologica, Suppl. I59.

Peirce, E. C., II (I95I). Percutaneous femoral artery catheterization in man with special reference to aortography. Surgery, Gynecology and Obstetrics, 93, 56.

Peirce, E. C., II, and Ramey, W. P. (1953). Renal arteriography: report of a percutaneous method using the femoral artery approach and a disposable catheter. Fournal of Urology, 69, 578.

Ross, R. S. (1968). Arterial complications. In Cooperative study on cardiac catheterization. Edited by E. Braunwald and H. J. C. Swan. Circulation, 37, Suppl. III, 39.

Seldinger, S. I. (1953). Catheter replacement of the needle in percutaneous arteriography: a new technique. Acta Radiologica, 39, 368.

Simovitch, H., Hohn, A. R., Wagner, H. R., Vlad, P., Subramanian, S., and Lambert, E. C. (1970). Percutaneous right and left heart catheterization in children: experience with 1,000 patients. Circulation, 41, 513.

Venables, A. W., and Hiller, H. G. (1963). Complications of cardiac investigation. British Heart fournal, 25, 334 .

\section{Requests for reprints should be addressed to Dr. U. Thadani, Research Fellow, Leeds General} Infimary, Leeds, Yorks.

\section{International Cardiac Meeting :}

\section{A Symposium on Surgical Heart Disease}

This symposium will take place on Monday, 2 I February to Friday, 25 February 1972, at Green Lane Hospital, Auckland, New Zealand.

The following subjects will be covered. Diagnosis and surgical management of congenital heart disease with particular interest in the newborn and profound hypothermia techniques; tetralogy of Fallot and transposition of the great vessels. There will be a half-day session on the physiology and practice of total body perfusion and the postoperative care of cardiac surgical cases. A whole day will be devoted to valve replacement, and the final day to the management of coronary disease including medical and surgical therapy.

The course is being arranged under the chairmanship of Sir Brian BarrattBoyes and Dr. J. B. Lowe.

Further information can be obtained by writing to Sir Brian Barratt-Boyes, Cardiothoracic Surgical Unit, Green Lane Hospital, Green Lane West, Auckland 3, New Zealand.

\section{Asian-Pacific Congress of Cardiology}

The V Asian-Pacific Congress will be held from 8-13 October 1972 in Singapore, under the auspices of the Asian-Pacific Society of Cardiology. These congresses are held at four-yearly intervals, and this one is being hosted by the Singapore Cardiac Society.

Further details of the programme and accommodation can be obtained by writing to: Organizing Committee, V Asian-Pacific Congress of Cardiology, c/o Faculty of Medicine, University of Singapore, Sepoy Lines, Singapore 3, Republic of Singapore. 